\title{
Development of a High Intensity EBIT for Basic and Applied Science
}

\author{
R.E. Marrs
}

D. Schneider

February 5, 1998

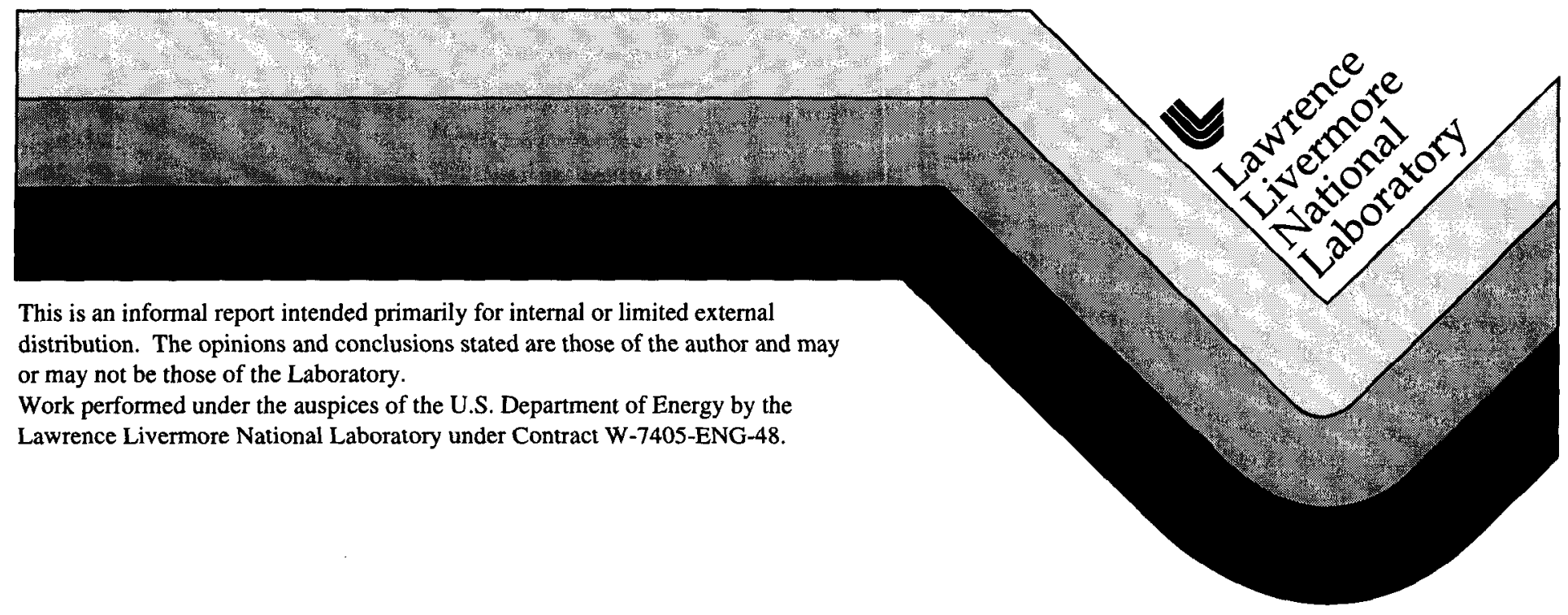




\section{DISCLAIMER}

This document was prepared as an account of work sponsored by an agency of the United States Government. Neither the United States Government nor the University of California nor any of their employees, makes any warranty, express or implied, or assumes any legal liability or responsibility for the accuracy, completeness, or usefulness of any information, apparatus, product, or process disclosed, or represents that its use would not infringe privately owned rights. Reference herein to any specific commercial product, process, or service by trade name, trademark, manufacturer, or otherwise, does not necessarily constitute or imply its endorsement, recommendation, or favoring by the United States Government or the University of California. The views and opinions of authors expressed herein do not necessarily state or reflect those of the United States Government or the University of California, and shall not be used for advertising or product endorsement purposes.

This report has been reproduced

directly from the best available copy.

Available to DOE and DOE contractors from the

Office of Scientific and Technical Information

P.O. Box 62, Oak Ridge, TN 37831

Prices available from (423) 576-8401

Available to the public from the

National Technical Information Service

U.S. Department of Commerce

5285 Port Royal Rd.,

Springfield, VA 2216 
UCR 129832

\title{
Final Report for LDRD Project 97-ERD-109 \\ Development of a High Intensity EBIT for Basic and Applied Science
}

\author{
Principal Investigator: R. E. Marrs \\ Co-Investigator: D. Schneider \\ Prepared February 5, 1998
}

\section{Introduction}

The electron-beam ion trap (EBIT) is a device for producing and studying cold, very highly charged ions of any element, up to a fully ionized $\mathrm{U}^{92+}$. These highly charged ions occur in hot plasmas and therefore play important roles in nuclear weapons, controlled fusion, and astrophysical phenomena. The remarkable interaction of these ions with surfaces may lead to technological applications. The highly charged ions can either be studied inside the EBIT itself with measurements of their $\mathrm{x}$-ray emission spectra, or the ions can be extracted from the EBIT in order to study their interaction with solid material. Both types of measurements are being pursued vigorously with the two existing low-intensity EBITs at LLNL and with similar EBITs that have been built at six other laboratories around the world since the EBIT was first developed at LLNL 10 years ago. However, all existing EBITs have approximately the same intensity as the original LLNL EBIT; that is, they all produce about the same number of very-highly-charged ions (roughly $2 \times 10^{6}$ per second) and the same number of x-ray photons (roughly $10^{7}$ per second).

The goal of the High-Intensity-EBIT project is to increase the $\mathrm{x}$-ray emission per centimeter of length along the electron beam by a factor of 100 and to increase the ion output by a factor of 1000 . This dramatic increase in intensity will enable the next generation of basic and applied experimental research in the structure of highly charged ions. For example, the precision of EBIT x-ray measurements of atomic energy levelswhich is now limited by count rate-can be improved by an order of magnitude, and new applications in surface science, nanotechnology, and microscopy will be possible with the expected intense ion beams. When the high ion output is combined with the 
demonstrated low emittance of EBIT ions, we will have a high-brightness source of highly charged ions that can be focused to submicrometer spots.

One example of a measurement that will benefit from increased $x$-ray intensity is our study of the binding energy of high- $Z$ heliumlike ions. The small "two-electron" contribution to this binding energy is a fundamental aspect of atomic structure. It arises from the small forces that the two electrons exert on each other in the presence of the much larger force from the atomic nucleus. Our existing EBIT measurements are sensitive to the so-called "second order" contribution to the two-electron binding energy, but with the High-Intensity EBIT we can probe an even more subtle effect: the screening by one electron of the quantum electrodynamic (QED) energy contribution from the other electron.

\section{Design of the High-Intensity EBIT}

Although the basic EBIT concept of highly charged ions trapped within the spacecharge potential of an electron beam remains the same, the design of our High-Intensity EBIT is very different from that of existing EBITs. We have made three significant changes to obtain higher intensity: (1) We doubled the magnetic field (from 3 to $6 \mathrm{~T}$ ) to obtain greater electron-beam compression; (2) We designed a new electron gun with a higher cathode brightness and a total electron current that is two times greater (and can be upgraded to ten times greater) than that of existing EBITs; and (3) We made the ion trap 10 times longer. The electron beam collector is designed to dissipate a power of more than $20 \mathrm{~kW}$ in order to handle the largest anticipated beam current. The cryostat has been designed for minimal consumption of liquid helium (we expect the High-Intensity EBIT to consume an order of magnitude less liquid helium than the existing LLNL EBITs), thereby greatly reducing a large operating expense.

\section{Accomplishments}

The development of the High-Intensity EBIT was approximately $90 \%$ complete at the end of FY 1997. Nearly all of the parts have been fabricated except for the drift-tube subassembly. We have completed and tested the electron gun, and verified that the measured compression of the electron beam in a magnetic field agrees with theoretical predictions. To measure the electron beam compression, we developed a novel $\mathrm{x}$-ray technique for studying electron beams injected into magnetic fields. 
The most critical component of the High-Intensity EBIT is the 6-T superconducting magnet. This magnet is of a unique design that is split into four coils to allow radial access at two different elevations: the midplane of the trap and a second location near the end of the trap. In spite of large gaps between the coils to facilitate $x-$ ray measurements, the 6-T magnetic field is uniform to within $1 \%$ over the $28-\mathrm{cm}$ length of the trap. The inside bore of the magnet bobbin is $10 \mathrm{~cm}$, a value large enough to allow the ion trap to float at very high voltage (up to $100 \mathrm{kV}$ ) or accommodate large-solid-angle $\mathrm{x}$-ray detectors for future coincidence measurements. The magnet will operate in persistent mode in a 50-liter liquid helium dewar.

We have also completed fabrication of the electron beam collector and most of the cryostat parts. The collector includes two water-cooled magnets that operate at room temperature. Like the electron gun, the collector is designed to float at voltages up to 200 $\mathrm{kV}$. When combined with the high voltage on the ion trap electrodes, this will result in an even higher electron beam energy than that of the LLNL Super EBIT.

EBIT devices are known to have a low emittance, which means that the ions extracted from them can be focused to a small spot with a small divergence. The large number of ions expected from the High-Intensity EBIT suggests that it could become a very bright source of highly charged ions. (Brightness is defined as the number of ions per second per unit area per unit solid angle.) One reason for the low emittance (high brightness) is the process of evaporative ion cooling that takes place in an EBIT trap. Suspecting that the brightness could be increased even further by self-cooling of the highly charged ions as they are released from the trap, we constructed a computer model of this process. The results indicate that the High-Intensity EBIT can be operated as a very-high-brightness source of highly charged ions. In fact, the brightness may be several orders of magnitude beyond what was previously suspected.

\section{Future Plans}

Although LDRD support for this project ended in FY 1997, we plan to complete the fabrication and assembly of the High-Intensity EBIT and begin initial experiments with the highly charged ions it produces. The expected capabilities of the High-Intensity EBIT will enable a new generation of basic and applied science with highly charge ions. 


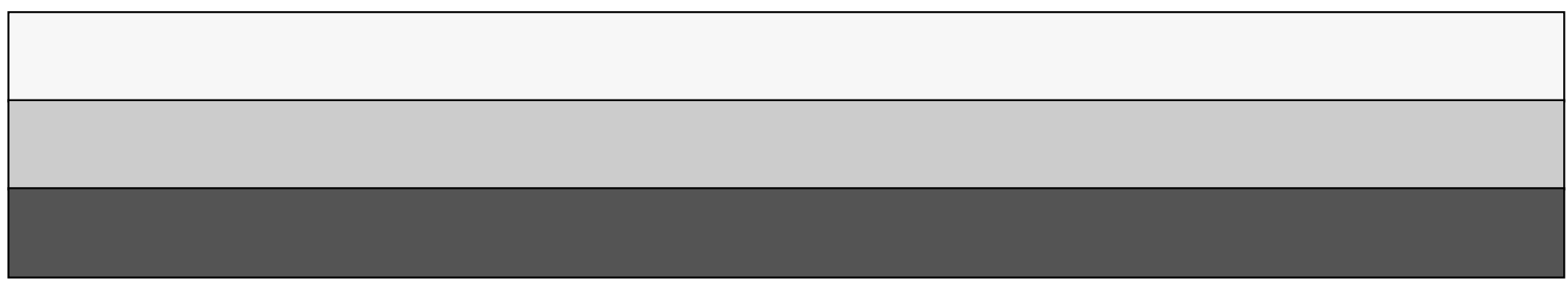

